\title{
A CORRUPÇÃO E A POSSIBILIDADE DA VIDA'
}

\section{CORRUPTION AND THE POSSIBILITY OF LIFE}

\author{
Veena Das*
}

Introdução

0 espectro da corrupção como um mal específıco da democracia na Índia assumiu um papel central nos empolgantes dramas políticos marcados pelo sucesso do Partido Aam Admi (AAP, na sigla em inglês) nas eleições para a Assembleia Legislativa de Deli, em 2013, e sua vitória espetacular, mais uma vez, em 2015. Embora este artigo não esteja preocupado com o destino do AAP, os dramas políticos oferecem uma visão fascinante do jogo entre uma política inspiradora e o realismo comum que marca a vida cotidiana (DAS, 2014). No início, a retórica política do movimento anticorrupção de Anna Hazare, em 2011, visava fundamentalmente os escalões superiores de políticos e burocratas, e sua agenda re- percutia profundamente nas aspirações da classe média por transparência na vida pública. Os antropólogos, principalmente os que trabalharam no sul da Ásia e na África, no entanto, pedem que suspendamos nossos juízos morais por um tempo, enquanto investigamos uma questão mais profunda: como podemos entender a corrupção como algo ancorado em práticas comuns e cotidianas? Segundo De Sardan (1999), antropólogo francês que cunhou a noção de “complexo da corrupção" na África para indicar as semelhanças de família entre diferentes tipos de práticas, por meio das quais as pessoas negociam a lei e a burocracia na vida cotidiana, o desafıo analítico consiste em evitar a dupla armadilha da condenação e do relativismo. Os limites entre o que é legítimo e ilegítimo, adverte

\footnotetext{
* Doutora em antropologia e docente e pesquisadora da Johns Hopkins University (Baltimore/Maryland/ USA). veenadas@jhu.edu.

1. Originalmente publicado na revista Contributions to Indian Sociology (vol. 49, 3, 2015). Agradecemos à autora Veena Das pela autorização para a tradução do artigo para o português e para a publicação na REPOCS.
} 
Sardan, não são estáveis, e tampouco podemos simplesmente recorrer a alguma noção geral de "cultura" africana para explicar a banalização da corrupção, sua cotidianidade e como ela passa a estar embutida nas noções de parentesco e obrigação. Com toda a sua banalização, a corrupção generalizada na política também é um convite à condenação dessa própria corrupção por parte das mesmas pessoas que poderão participar da subversão das regras impessoais, para obter ganho pessoal ou por outras razões socialmente aceitas. No mínimo, portanto, somos obrigados a investigar as condições de possibilidade para o desenvolvimento desses impulsos contraditórios no mesmo mundo social.

A vida cotidiana, contudo, é um conceito notoriamente difícil de pesquisar em nível empírico, pois nos pede que tornemos visível não o que está oculto, mas o que é certo diante de nossos olhos (DAS, 2014). Dessa perspectiva, o aspecto mais interessante da corrupção é que ela é banalizada e condenada ao mesmo tempo. As mesmas pessoas que se manifestam sobre o declínio da força moral do país em um registro de fala deixam de observar suas próprias ações ou encontram sustentação para elas em outro conjunto de normas, por exemplo, o das normas baseadas em parentesco e comunidade. De Sardan (1999) e Alpa Shah (2010) usam, ambos, o conceito de economia moral (interpretado de forma ampla) para mostrar como normas e valores são expressos de forma a criar essa dupla valência com a qual a corrupção é vista. David Sneath (2006) sugere que as linhas entre um presente (dom) honesto e a extorsão ilegítima na forma de subornos podem ser situadas em um espectro ético, em vez de em categorias distintas. No caso de seus locais de pesquisa de campo na Mongólia,
Sneath afirma que o colapso do socialismo é que teria transformado a textura de transações entre pessoas comuns e autoridades, que passou de presentes a subornos.

\section{Corrupção e honestidade: emoções ema- ranhadas}

Para meu próprio esclarecimento com relação ao conjunto de questões levantadas pelos impulsos contraditórios que mencionei acima, começo com um texto literário - a merecidamente famosa história de autoria de Munshi Premchand, Namak ka Daroga (0 superintendente do sal), publicada em 1907, em Hindi/Urdu (PREMCHAND, 2009 [1907]). Segundo a crítica literária e escritora Ruth Vanita, essa história atesta a sensibilidade gandhiana de Premchand, segundo a qual qualquer um a quem se confie autoridade estará à altura da tarefa (VANITA, 2008). Na realidade, Premchand (2009) tem outras histórias nas quais a moral se introduz quase contra a vontade da pessoa, quando ela é elevada, digamos, à posição de um panch - um membro do tradicional conselho de aldeia formado por cinco pessoas, através das quais a verdade falaria (por exemplo, na história Panch Pyare [Os cinco amados]). Contudo, eu diria que Namak ka Daroga é um exemplo da bitextualidade típica da figura de linguagem conhecida como shlesha alamkara, na estética sânscrita e hindi, onde o sentido explícito cria outro, sugerido, com a repetição da mesma palavra, assim como um som produz um eco. No entanto, não é em palavras específicas, nem mesmo em momentos distintos do texto, e sim na experiência do texto como um todo que vemos como corrupção e honestidade estão emaranhadas dentro de um redemoinho de emoções, que não são visíveis à primeira vista. 
A história se passa no início do século $\mathrm{XX}$, e começa com a criação de um novo departamento para monitorar a movimentação de sal, tornada ilegal pela cobrança de um imposto sobre o produto pela Companhia Britânica das Índias Orientais e, apesar dos protestos, mantido pela Coroa quando ela assumiu a administração dos territórios da Índia Oriental, em 1858.

Como nos conta o narrador, o que antes fizera parte do comércio normal era agora regulamentado, e as pessoas tinham que realizar sua atividade normal no comércio de sal manipulando suas conexões ou distribuindo subornos. Como resultado, os empregos no novo departamento eram muito procurados em função das possibilidades de lucro que ofereciam. Munshi Vanshidhar, o protagonista dessa história, teve a sorte de ser nomeado o novo inspetor do sal. Inicialmente, a história descreve uma cena doméstica - um pai dando conselhos ao filho que vai procurar um emprego público. Nas palavras de Premchand (2009):

0 pai de Vanshidhar era um homem experiente, e começou a aconselhá-lo: 'Meu filho, veja os tempos difíceis em que vivemos. Estamos sendo esmagados pelo peso de nossas dívidas. As meninas... elas estão crescendo rápido como o capim e o inço na floresta. Eu sou uma árvore velha que está na margem de um córrego, e quem sabe quando eu vou ser arrancado? Agora você é o dono e o senhor desta casa. Ao procurar o serviço público, não pense em um cargo alto ou baixo. Esses são os mazars (santuários) do pir (santo) - sua visão deve estar dirigida às ofertas de dinheiro e presentes (nazar chadave aur chaddar par chaahiye rakhni). Fique com o tipo de trabalho em que haja algum espaço para renda extra (aay uppari, um eufemismo para subornos).
A renda extra é como uma fonte de água corrente: sempre sacia a nossa sede'.

A seguir, a voz do narrador nos diz que Vanshidhar era um filho obediente. Ele ouviu essas palavras com atenção e, em seguida, foi embora. Quando chegou a notícia de que ele fora nomeado superintendente do sal, seu pai ficou muito feliz. 0 agiota afrouxou a pressão pelo pagamento das dívidas, enquanto os vizinhos ficaram com inveja da sorte que caíra no colo da família. Tudo parecia estar indo bem e, então, na parte intermediária da história, surge uma tensão na narrativa. Uma noite, Vanshidhar é despertado por um som constante de veículos se movimentando nas proximidades do rio Yamuna, perto da ponte dos barcos. Ao perguntar a seus subordinados sobre o que está acontecendo, ele é informado de que o ruído é proveniente dos homens de Pandit Aalopadin. Quem é esse Pandit Aalopadin, ele pergunta. Há um silêncio de espanto, e alguém lhe informa que Aalopadin é o mais poderoso zamindar da região, de cuja hospitalidade as autoridades britânicas desfrutam rotineiramente. Sem vacilar, Vanshidhar veste sua farda e sai para investigar. Ele descobre que o sal está pronto para ser transportado por balsas à vizinha cidade de Kanpur, sob o manto da escuridão, a fim de evitar os impostos, e fica furioso com essa evidência de desonestidade e descumprimento da lei. Em voz estrondosa, ele pede que o sal seja confiscado e os homens, presos. Mensagens apressadas são enviadas ao zamindar Pandit Aalopadin, que fica estupefato ao saber que alguém se atrevera a prender seus homens, pois ele havia garantido que todos os funcionários do governo recebessem dinheiro dele; ao perceber que Vanshidhar é novo 
no emprego e que provavelmente ainda não conhece as regras do jogo, oferece um suborno considerável. Vanshidhar rejeita a oferta de forma arrogante. Como a oferta continua aumentando cada vez mais e Vanshidhar se recusa a sequer considerar o que já é uma quantidade colossal de dinheiro, Pandit Aalopadin muda de estratégia e passa a suplicar com humildade, mas Vanshidhar, inabalável, algema-o e pede que seu pessoal de apoio o conduza à cadeia. Todo mundo está surpreso e estupefato por Vanshidhar ter ousado insultar um homem tão poderoso. Inevitavelmente, o episódio avança rumo a seu fim previsivel. $\mathrm{Na}$ audiência contra Pandit Aalopadin, as testemunhas haviam sido subornadas e se voltam contra Vanshidhar. 0 caso é encerrado e Vanshidhar perde o emprego, sendo advertido pelo juiz para que não incomodasse cidadãos honestos. Se a história tivesse terminado aqui, teria sido uma simples história de moral sobre corrupção no Estado com o preço que os funcionários honestos têm que pagar por sua integridade. Porém, como veremos, não é o caso.

Gostaria de fazer uma pausa e apresentar o tipo de fala que marca a interação entre Vanshidhar e Pandit Aalopadin na cena em que o segundo é pego contrabandeando sal:

Pandit Aalopadin disse com humildade:

Babu Saheb, por favor, não faça isso [ou seja, algemá-lo]. Nós seremos destruídos. Nossa honra vai virar pó. 0 que você vai conseguir nos insultando? E nós não somos, de modo algum, diferentes de você [sugerindo eles $f a-$ zem parte da mesma comunidade moral].

Vanshidhar respondeu com arrogância:

Nós não estamos entre os que vendem sua honestidade por ninharias.
Agora, vejamos o que acontece quando Vanshidhar, em desgraça e sem emprego, volta para casa:

Seu pai lamentava sua própria desgraça: Que tipo de filho eu criei! Não importa que esteja escuro em casa, o honrado Senhor (Sir) tem que acender uma lâmpada na mesquita! Aqui estou eu, velho, perto da morte e apenas com o salário oficial, seco.

0 final surpreendente da história é que Pandit Aalopadin, libertado da prisão com a honra intacta, vem à aldeia de Vanshidhar em sua carruagem com todo o esplendor. 0 pai de Vanshidhar corre para cumprimentá-lo e, caindo a seus pés, pede perdão pela audácia e a loucura de seu filho. "Não, não", diz Aalopadin, "seu filho é o farol que ilumina sua linhagem, uma honra aos seus antepassados".

Enquanto um envergonhado Vanshidhar sai para cumprimentá-lo e cai a seus pés pedindo perdão, Aalopadin tira um documento oficial e carimbado, no qual está escrita uma oferta de emprego como administrador de sua propriedade, e o entrega a Vanshidhar. Enquanto isso, Aalopadin lhe diz:

Eu já vi muitos guerreiros, e não há nenhum que eu não tenha conseguido comprar com o meu dinheiro. Mas você manteve a sua honestidade; não importando o que eu oferecesse, você não cedeu à tentação. Como eu vou encontrar uma pessoa melhor do que você para administrar a minha propriedade?

Prestemos atenção, mais uma vez, às palavras ditas:

Vanshidhar: 0 desrespeito que eu demonstrei, por favor, me perdoe por isso. Eu estava preso às correntes do darma, mas fora is- 
so, eu sou seu escravo/servo. Tudo o que você mandar fazer, eu vou aceitar como uma bênção [literalmente, na minha testa e na minha cabeça - sarmaathe par - uma expressão que indica que a ordem é tomada como se estivesse escrita no corpo, como algo que fora predestinado].

Pandit Aalopadin tira o documento carimbado e diz: "Por favor, aceite este cargo (como administrador de sua propriedade) e assine aqui. Eu sou um brâmane, e não sairei da sua porta enquanto você não preencher esta coluna [com sua assinatura]”.

\subsection{0 enigma}

Poderíamos interpretar essa história como uma afırmação de que a honestidade acaba compensando, porque Vanshidhar é premiado com um emprego ainda mais lucrativo do que o que ele tinha como inspetor do sal. Contudo, pode ser mais interessante analisar as emoções contraditórias evocadas pelas palavras realmente ditas. Devemos nos lembrar de que Premchand é um mestre da sugestão, que consegue usar as palavras literalmente para criar uma dissonância nas ideias que recebemos sobre quais palavras conseguem evocar quais tipos de cenas ${ }^{3}$. Sendo assim, vejamos onde essa dissonância é criada, pois temos não apenas uma, mas várias perspectivas, e mudanças rápidas entre elas na história.

0 que é um emprego público? De acordo com o pai de Vanshidhar, é um rio que flui, do qual se pode beber permanentemente sem lhe esgotar a água. 0 emprego público também é descrito como um santuário, onde os fiéis trazem presentes na forma de oferendas e, em troca, obtêm o que desejam. Vanshidhar é um filho obediente e entende bem o conselho do pai. No entanto, quando veste a farda de policial, o darma de um mundo burocrático diferente o possui, quando ele se torna o aplicador correto da lei. Ele deixa todos espantados com sua arrogância, e trata o zamindar como um criminoso comum. Sua retidão é interpretada por seu pai como arrogância tola. A frase irônica "não há luz na casa, mas o honrado Senhor tem que acender a lâmpada na mesquita” expressa a visão comum de que um ato, que pode ser meritório em si, é inadequado em circunstâncias de vida comum. Parece dizer que, se você é um castor, não finja ser capaz de construir uma barragem nem leve a culpa por não ter sido capaz de fazê-lo.

Será que Vanshidhar tem uma voz coerente, portadora da virtude da honestidade de um contexto para outro? A resposta, mais uma vez, deve ser sim e não. Diante de Pandit Aalopadin, na aldeia, Vanshidhar, agora sem sua farda, arrepende-se de sua falta de vinay (cortesia, honestidade) quando falou com a voz áspera (kadak aawaz) da autoridade, mas alega que estava preso às correntes do darma. Liberto daquela farda, o mesmo Vanshidhar declara ser um servo e um escravo pronto para realizar qualquer ordem que Pandit Aalopadin lhe desse. Sendo assim, ele não nega o seu eu anterior, mas, à medida que o contexto muda, parece-lhe correto ser uma pessoa diferente em uma relação diferente com o mesmo homem que ele havia detido por contrabando. Agora, examinemos

3. Por exemplo, em vez de usar urdu, Premchand usa um vocabulário altamente sanscritizado, contrário às expectativas de uma divisão linguística entre hindus e muçulmanos, para desenhar a cena de uma celebração do Eid (Festa do Sacrifício) em sua história com o mesmo nome. 
o gesto e as palavras de Pandit Aalopadin. Ele se baseia na visão tradicional do brâmane cuja hatha (insistência), em um determinado curso de ação por meio do gesto de súplica, pode colocar de joelhos os mais poderosos. Assim, ele diz: "Eu sou um brâmane e não sairei da sua porta até que você tenha assinado este papel”. Ao mesmo tempo, evoca o documento oficial e carimbado, também evocando, nesse gesto, a autorização de contratos (por exemplo, como na assinatura de uma carta de nomeação) por meio das tecnologias de escrita do Estado. Aqui está um exemplo das múltiplas temporalidades nos atos de condensação do gesto de satyagraha ou hatha do brâmane (insistência através do gesto de súplica) e a forma estatal de autorização por meio de assinatura em um papel carimbado. Por fim, o que Vanshidhar está aceitando ao assinar esse contrato? A partir de episódios anteriores da história - quando, por exemplo, Pandit Aalopadin tinha repreendido seu munshi (contador) por dois sacos de sal que faltavam em seu godaam (armazém) - sabemos que ele valoriza a honestidade acima de tudo e está à procura de um homem honesto para administrar sua propriedade, e não quer oferecer emprego com base em relações de casta ou de parentesco. No entanto, a virtude da honestidade, para Vanshidhar, residirá em servir a um mestre que comprovadamente contrabandeia sal e compra policiais e testemunhas. Porém, Vanshidhar não é o mesmo homem que disse não ser dos que vendem sua iman (reputação de honesto) por ninharias? E, sendo assim, essa forma de desonestidade que ele estrondosamente deplorara desapareceu? 0 sentido geral do texto é que Vanshidhar encontrou o lugar certo para sua honestidade, e não que ele tenha traído um eu anterior.
0 que podemos concluir dessa breve discussão sobre os enigmas que encontramos na história? Em primeiro lugar, aprendemos que as recompensas do Estado não fazem parte de qualquer sistema ordenado e regulado de regras, e sim, são um pouco como as recompensas imprevisíveis que se podem obter das bênçãos de um pir. É por isso que o salário é sookhi (seco), enquanto a renda extra que flui é verde e florescente. Em um determinado momento, o pai de Vanshidhar compara o salário regular de um funcionário público à lua cheia: ela acende a noite totalmente, mas apenas por uma noite e, em seguida, míngua - uma referência ao fato de que se é pago no primeiro dia do mês, que é como a noite de lua cheia e, em seguida, os recursos mínguam. 0 aay upari (renda extra) que vem continuamente com um emprego público, na forma de subornos, é o que fornece os recursos para cuidar-se - ela cresce, pode fazer com que irmãs solteiras se casem, pode comprar tempo dos credores. Porém, a honestidade oficialmente exigida de um funcionário público pode vir a possuir uma pessoa. Uso aqui a ideia de posse porque, embora você possa falar usando a voz de um espírito ou um de deus, essa voz não é sua, e pode ser descartada quando a vida cotidiana for retomada, e se entrar no fluxo de um tipo diferente de tempo e um conjunto diferente de relações. Vanita tem razão ao detectar a sensibilidade gandhiana segundo a qual uma pessoa não é intrinsecamente boa ou má - a pessoa cresce diante das circunstâncias, independente de sua vontade. No entanto, ao contrário da outra história (Panch Pyare) a que me referi anteriormente, na qual uma pessoa nomeada ao Conselho da Aldeia para julgar um caso descobre que a verdade fala por sua boca, no caso de Vanshidhar, as correntes 
daquele darma impessoal perdem sua força quando ele volta à sua aldeia e confronta Pandit Aalopadin dentro da moralidade do sistema local de castas e zamindari ${ }^{4}$ o que esse texto literário pode nos ensinar sobre os contornos da corrupção da forma como os encontramos hoje?

\subsection{0 literário e o etnográfico}

Explorando a profunda relação entre literatura e etnografia, Didier Fassin (2014) afirma que o que elas têm em comum é a base de seus respectivos projetos estéticos e intelectuais. Essa base, Fassin sustenta, é a própria vida. Marc Augé (2011) também fala do diálogo silencioso entre antropólogos e obras de ficção. Outros antropólogos, principalmente Michael Jackson (2013) e Vincent Crapanzano (2003), estabeleceram a afinidade entre literatura e antropologia como parte integrante da forma antropológica de saber. No meu trabalho, pareceme que recorremos aos poetas para que nos deem palavras quando nós mesmos tropeçamos diante da violência e do sofrimento (DAS, 2007). Em grande parte deste texto, considera-se que a conversa entre literatura e antropologia acontece no espaço entre o trabalho de campo e a escrita, ajudando nos modos de interpretação, fornecendo palavras quando nossos próprios vocabulários falham ou considerando que o literário fornece um modelo para construir 0 texto antropológico. Neste artigo, porém, estou interessada em dois níveis diferentes nos quais essa conversa se torna possível: um, quando encontramos expressões literárias e filosóficas na fala dos entrevistados, e outro, quando vemos os escritores como companheiros de viagem cuja apresentação estética do que está acontecendo nos proporciona compreensões sobre como despertar para o mundo que nós, como antropólogos, podemos tentar revelar em nossa própria escrita.

Uma compreensão impressionante que a história de Premchand (2009) nos proporciona é que há diferentes aspectos do indivíduo que surgem ou são eclipsados na densidade dos relacionamentos, mas seu entendimento vai em uma direção diferente do cumprimento de papéis. A noção de Roy Wagner (1991) de uma pessoa como sendo "fractal" parece oportuna aqui. Em suas palavras: "Uma pessoa fractal nunca é uma unidade independente em relação a um agregado [leia-se indivíduo em relação à sociedade ou a um grupo] ou um agregado em relação a uma unidade, mas sempre uma entidade com uma relação integralmente implícita" (WAGNER, 1991, p. 163). A noção de pessoa de Premchand (2009) parece ainda mais complexa, pois, na figura do inspetor do sal, vemos não apenas que partes do outro são partes integrantes de nós mesmos, mas também que uma nova norma - relativa à maneira impessoal como uma autoridade do governo deveria aplicar uma lei -, se apossa de Vanshidhar. A norma assimila, em si, noções do darma e imaan sobre ideias de moral adjacentes, mas diferentes, de modo que Vanshidhar está mais expressando, simultaneamente, essas ordens normativas diferentes do que escolhendo entre elas. Lembremo-nos de sua declaração de que ele não está entre os burocratas que venderiam sua imaan por ninharias, bem como sua explicação posterior sobre seu comportamento arrogante

4. Sistema indiano de coleta de impostos em que um homem (zamindar) era responsável por um determinado território e pela cobrança de impostos sobre ele - NT. 
- "Eu estava preso às correntes do darma". Entretanto, uma vez libertado dessas correntes ao ser demitido de seu cargo, com a advertência de que não deveria perseguir cidadãos honestos e respeitáveis como o acusado Aalopadin, ele está pronto para servir à mesma pessoa, com a mesma honestidade, agora voltada às expectativas de seu novo empregador. Teria sido fácil interpretar essa história como um conflito de normas representadas pelas diferentes personagens da história se Vanshidhar tivesse permanecido estável em sua visão do que se entende por darma-imaan. Na verdade, estudiosos como De Sardan (1999) argumentam que a corrupção pode florescer em contextos onde existe uma pluralidade de leis e regras contraditórias, de modo que essa corrupção possa ser sempre justificada como uma forma de negociação entre esses diferentes tipos de regras. Todavia, o que está em jogo aqui é que os conceitos de temporalidades muito diferentes, com suas próprias histórias - e darma e imaan são dois exemplos - são amarrados um ao outro, em um contexto totalmente novo das leis do sal dos britânicos, que é a chance de explorar novas oportunidades econômicas, por meio de contrabando e o retrato dramático do eixo sobre o qual gira a respeitabilidade de Pandit Aalopadin. Se fosse condenado, ele se tornaria um criminoso; libertado, aumentaria sua reputação de que nenhuma pessoa, por mais poderosa que fosse, poderia tocá-lo. Aqui, o julgamento de caráter funde a noção de rosto com a de comportamento pessoal na determinação da virtude (SELBY, 2015). Quando Pandit Aalopadin implora a Vanshidhar, dizendo aapko hamari badnami karake kya milega [o que você vai ganhar manchando o meu nome], o que está em jogo é a honra e não a virtude pessoal. A história é uma lição sobre o que é ser, simultaneamente, sujeito do direito e objeto de darma e imaan. Há múltiplas soberanias em jogo aqui, não só em nível de estruturas de autoridade do Estado e do direito, mas também no da pessoa ${ }^{5}$. Ao ler essa história (mais uma vez, como adulta), fiquei impressionado com os poderosos sentimentos que cada palavra porta e sua capacidade de nos fazer viajar no tempo, como quando a referência de Pandit Aalopadin ao hatha (insistência) do brâmane nos levou próximo a um mundo em que um brâmane pode usar esse gesto profundamente enraizado de súplica, arrogante como arma, ao colocar seu corpo contra a vontade do outro.

\subsection{A potência de palavras}

Grande parte da discussão sobre corrupção na literatura antropológica tem se baseado no que Alpa Shah (2010) chama de narrativização da corrupção, ou seja, é a forma como as pessoas falam sobre a corrupção dos outros que fornece a base para a teorização. Assim, Akhil Gupta (1995) argumenta que quando aldeias em Uttar Pradesh falam de corrupção nas altas esferas estão se imaginando em uma relação íntima com o Estado ao participar dos rumores sobre a forma como esse Estado é gerido. Embora Jonathan Parry (2000) conteste Gupta, dizendo que os moradores das aldeias de Chhattisgarh falam de corrupção em tons visivelmente morais de condenação, ele

5. Ver, também, Betlem (2015), para uma análise penetrante da maneira em que afirmações sobre a lei e afırmações da vida passam continuamente de uma para a outra 
também está se baseando em "conversa de corrupção" quando é o comportamento dos outros que está sendo examinado. Shah (2010), por outro lado, descreve a economia moral (em um sentido amplo do termo) dos projetos de desenvolvimento nos quais atos como o desvio de dinheiro por empreiteiros locais ocorrem enquanto ela (como a antropóloga que observa) está bem no meio da situação em que esses projetos estão sendo implementados. No entanto, ela também se baseia em entrevistas nas quais se pede que os informantes verbalizem sua própria visão ou apresentem suas opiniões em resposta à formulação dela sobre as questões de corrupção. Isso dá uma clareza muito maior às visões de seus informantes do que a que é encontrada quando se está imerso no dar e receber da conversa na vida cotidiana. As diferenças são tão sutis, que eu só consigo mostrá-las fazendo uma exposição detalhada de uma cena específica, no livro de Shah, comparando-a com a forma como a voz pode ser usada quando o equilíbrio se desloca a um modo no qual estamos pedindo aos nossos informantes para nos ajudar a ver o que está acontecendo, em vez de pedir opiniões.

A cena inicial do capítulo 3 de Shah (2010) sobre corrupção acontece em sua casa, quando um empreiteiro da aldeia, chamado Dharmesh, a visita e eles tomam chá sentados no chão de barro da casa. Dharmesh, somos informados, foi escolhido como o empreiteiro local que irá implementar um projeto de construção de estradas do Ministério do Desenvolvimento Rural.

Mas como você vai economizar 10.000 rúpias construindo essa estrada, perguntei a
Dharmesh. Antes que ele pudesse responder, acrescentei: "Me parece que os seus primos Neel e Anand foram bastante espertos em relação a esse projeto. Eles sabem que não poderiam ter sido escolhidos como empreiteiros desta vez, já que o resto de vocês [os filhos de Tapu ${ }^{6}$ armaria uma grande confusão se eles continuassem colhendo os benefícios dos recursos do sarkari (governo). Então, em vez disso, eles propuseram uma condição à qual nenhum de vocês poderia se opor: os empreiteiros tinham que dar 10.000 rúpias para construir o templo de Hanuman, juntamente com todos os subornos e as porcentagens que você terá que dar aos supervisores do distrito. Como vai conseguir guardar a sua parte, nessas condições?

Diante da indagação de Shah, apresentada dessa maneira, Dharmesh passa a explicar que vai dar aos adivasis que estão trabalhando como operários 50 rúpias por dia em vez do pagamento estipulado, de 150 rúpias, e também economizará usando materiais precários e outros truques contábeis com os quais mostrará que o trabalho demorou mais do que sua duração real.

A questão é que as perguntas de Shah descrevem a situação como já decifrada, e pedem respostas dentro desse quadro. Eu parto do princípio de que as pessoas não falam realmente dessa maneira na vida cotidiana, mas costumam usar frases enigmáticas curtas, nas quais não é preciso explicitar um entendimento comum sobre o pano de fundo compartilhado. A continuidade das relações garante que o contexto esteja implícito na conversa. No modo de questionamento de Shah, ou pelo menos na forma como ela apresenta sua pergunta,

6. Os sadans são a elite local, descendentes dos colonizadores, e empregam adivasis como trabalhadores. 
a fala parece ser também para o forasteiro que tem de ser informado sobre o que está acontecendo. Não significa que as respostas estejam incorretas, e sim que a linguagem em que são dadas se torna muito mais transparente do que costuma ser.

Como exemplo do jogo entre opacidade e transparência, cito o seguinte caso do meu trabalho de campo, em que a referência a um personagem mítico consegue criar um sentido em que a corrupção, em vez de ser um atributo de pessoas, torna-se um atributo do emaranhado de relações dentro de um determinado tipo de ambiente.

Conversando com um líder local muçulmano em um bairro de baixa renda em Deli, composto de artesãos, artistas e titereiros de rua, bem como de migrantes de Bihar que faziam trabalhos humildes, não qualificados e mal pagos, eu lhe perguntei como ele chegara a ter tanta influência. Hesitando um pouco, indaguei: "Há alguma tensão criada pelo fato de você ser muçulmano e morar em um bairro onde predominam hindus?" Dizia-se que a principal característica desse líder era ser muito hábil para lidar com a polícia local e para dar conselhos às pessoas que tinham se envolvido em algum crime menor e precisavam de um mediador para lidar com os policiais. Ele também escrevia poesia e conseguia se divertir em competições poéticas improvisadas, muito apreciadas por multidões que esperam os grandes homens chegarem durante comícios eleitorais. Ele sorriu e disse: "Eu sou o Shakuni Mama deles (tio materno do rei Duryodhana no Mahabharata)". Essa resposta me pareceu condensar o presente e o passado, a lógica do Estado e a da mitologia. Mas quando eu lhe pedi que explicasse o que dissera, ele apenas sorriu e disse: "Agora você pode entender o que quiser" (ab jo marzi samajh lo). No meu en- tendimento, os personagens que aparecem no Mahabharata entretecem momentos que estão em tempos diferentes para criar múltiplas vertentes em uma história, de modo que a ideia de unidade em uma personagem dá lugar a uma multiplicidade que nos impele de uma interpretação a outra. Shakuni Mama era o tio astuto de Duryodhana, o principal adversário dos Pandavas. Ele era o irmão de Gandhari, a rainha do rei cego Dhritarashtra e mãe dos Kauravas. Shakuni é retratado no texto como um homem extremamente inteligente, mas desonesto, que gostava muito de seu sobrinho Duryodhana. Ele conquistou o reino dos Pandavas para o sobrinho manipulando Yuddhishthira, o mais velho dos irmãos Pandavas, para que apostasse seu reino em um jogo de dados fraudado. Os dados que foram usados haviam sido feitos com os ossos da coxa do pai de Shakuni e sempre faziam o que ele queria. Como acontece com todos os personagens do épico, Shakuni também faz parte de outra história em que o marido cego de Gandhari, Dhritarashtra, descobre que ela havia sido casada anteriormente com um bode, em um casamento simbólico para enganar o seu destino, no qual estava escrito que seu marido morreria logo após o casamento. Porém, ao ouvir esse episódio, Dhritarashtra fica furioso ao saber que não era o primeiro marido dela. Em um ato de vingança, ele aprisiona todos os parentes de sangue de Gandhari. Shakuni foi o único de seus cem irmãos a sobreviver na prisão, pois todos os outros abriram mão de suas refeições para que ele pudesse vingar a morte de seus parentes. Sendo assim, o papel de Shakuni no jogo de dados pode ser visto como o trabalho para intensificar o conflito entre os Pandavas e os Kauravas, pois ele sabia que essa guerra levaria à destruição completa da linhagem de Dhrita- 
rashtra. 0 texto nos deixa com um enigma: a razão pela qual ele instigou Duryodhana para que usurpasse o reino dos Pandavas ilegalmente foi seu amor por Duryodhana ou seu ódio a Dhritarashtra? Eu invoco a história simplesmente para mostrar que, na personificação do líder muçulmano como Shakuni Mama, as pessoas do bairro indicam a necessidade de um homem ardiloso, mas brilhante, para lidar com as agências do Estado, além de permitir um comentário sobre a complexidade das relações entre hindus e muçulmanos. De que forma Ghulam Ali, o líder local, é criado pelos tempos em que vivemos? Curiosamente, não é com longas explicações de suas ações que as pessoas mostram o quanto são complexas as suas compreensões da corrupção com relação aos órgãos do Estado, e sim permitindo que as referências mitológicas proporcionem um comentário social sobre as condições em que a corrupção está envolvida na vida cotidiana.

\subsection{0 próximo e o distante}

Shah (2010) faz a observação perspicaz de que, embora possa ser útil considerar a corrupção como participação na economia informal do Estado, houve diferentes normas locais dentro das quais essas ações poderiam ser justificadas. "Assim, a moral, no discurso da corrupção, muitas vezes era julgada no contexto de valores como casta, negociabilidade, dar presentes, hierarquia e ganância” (SHAH, 2010, p. 79). 0 próximo exemplo que eu apresento está mais relacionado à própria defınição da corrupção em si do que à justificação da corrupção. Sanjeev Gupta, um dos líderes locais de Punjabi Basti, um bairro de baixa renda, que tem trabalhado diligentemente ao longo dos últimos dez anos para que o status do bairro passe de colônia não autorizada a colônia autorizada, contou-me suas ideias sobre a corrupção depois da vitória eleitoral do AAP, em 2013. Na verdade, eu o ajudei a traduzir algumas das suas ideias sobre a situação política em um artigo de opinião que foi publicado em um jornal de circulação nacional (GUPTA, 2014). Gupta representa um tipo de envolvimento com o Estado,que é diferente do de Dharmesh, interlocutor de Shah em seu livro, porque ele (Gupta) tem trabalhado para obter serviços públicos, como eletricidade e água, através das redes de membros dos partidos políticos e representantes eleitos desse distrito. No processo, ele usou vários mecanismos disponíveis que vão desde entrar com ações nos tribunais a abaixo-assinados dirigidos a vários políticos e burocratas pedindo fornecimento de serviços públicos na "colônia não autorizada” (DAS; WALTON, no prelo). Gupta afirma que o problema do ardente desejo da classe média por uma sociedade livre de corrupção é a falta de entendimento sobre o quanto é fácil fazer com que o próprio processo de subsistência dos pobres pareça corrupção. Na verdade, ele está convencido de que, como agenda política, a centralidade dada às investigações sobre corrupção vai levar a uma erosão das possibilidades de participação política para os pobres. Esta é sua explicação dessa interpretação pouco ortodoxa sobre o que os outros veem como um momento de transformação na política indiana:

Os líderes do Aam Admi prometem que se uma solicitação de cartão de alimentação não for processada em dez dias, o burocrata responsável pelo atraso será punido. Então quando é que o funcionário encarregado (adhikari) diz que não vai processar o pedido em dez dias? Mas o que ele pede é um com- 
provante de residência. Você lhe diz que é dono da sua casa e ele pede uma prova, mas as casas onde nós moramos estão em terras ocupadas. Eu diria que 70\% de Deli vivem em terras ocupadas (kabze ki zameen). É verdade que nós não obtivemos essas terras legalmente, toda a nossa colônia está em terras ocupadas. Mas nos últimos 30 anos, nós derramamos sangue e suor (khun pasina bahaya hai) para tornar esta terra habitável. Os tribunais já se pronunciaram, dizendo que quem tivesse residência contínua, mesmo em terras ocupadas, não poderia ser despejado sem uma residência alternativa, mas o burocrata também não está errado, pois nós realmente vivemos em terra ocupada ilegalmente. Então, como é que nossos cartões de alimentação foram emitidos ou nós abrimos contas bancárias? É porque um MA (membro da Assembleia Legislativa) ou MP (Membro do Parlamento) autorizou as nossas assinaturas e instruiu os funcionários a nos dar esses documentos. A mesma coisa acontece com a água - o Conselho de Água de Deli nos diz que, como colônia não autorizada, nós não temos direito de receber água e, portanto, eles não podem nos fornecer água encanada. Mas então nós devemos morrer de sede? Nós agitamos e escrevemos petições, e nossos MAs e MPs, que entendem os nossos problemas, autorizaram três poços na área embora seja ilegal, em Nova Deli, cavar poços devido ao esgotamento da água subterrânea - porque o MA quer votos. 0 MA ou o MP que ordenou que esses poços fossem escavados com dinheiro público é corrupto? Nós não chamamos isso de corrupção. Dizemos que essas ações permitem que o pobre ganhe a vida, crie seus filhos para poder viver melhor. Como isso pode ser corrupção?

Contudo, há outras ocasiões nas quais Gupta falou da máfia bhu local (máfia da terra), que está implicada na ocupação de terras do governo e sua venda a pessoas, com a conivência da polícia e dos políticos. Ele percebe que esses são os mesmos políticos que ele elogiou por ignorar a lei contra a abertura de poços, mas que estão em sintonia com as necessidades que devem ser atendidas para que a vida seja sustentada. As declarações mais ambíguas de Gupta a respeito do perigo do combate à corrupção se referiam ao projeto mais bem sucedido na localidade da qual ele era uma liderança exemplar: o de regularizar o fornecimento de energia na área. Em outro momento, descrevi os enormes esforços desenvolvidos por Gupta e outros líderes locais, bem como o intrincado domínio das redes que Gupta exibia, que tornou possível que esse projeto fosse levado a cabo (DAS, 2014). A seguir, apresento a essência das atividades, em função do quanto ajudam a entender a complexa relação com o complexo da corrupção e a dificuldade de condenar essas ações a partir de uma posição de inocência para aqueles que estiveram ativamente envolvidos na excitante ação política do tipo que é necessário para tornar sua área habitável. A seguir, a história.

0 processo de regularização de eletricidade neste bairro começou com a privatização da energia elétrica em Nova Deli, entre 2000 e 2002. Quando as reformas de energia começaram na cidade, à luz das evidências de roubo generalizado de energia elétrica e as pesadas perdas incorridas pela estatal Delhi Vidyut Board, esta foi desagregada em três empresas privadas. Sanjeev Gupta e muitos outros me contaram sobre as terriveis perseguições que os moradores enfrentaram quando funcionários da empresa privada apresentaram denúncias à polícia sobre roubo de eletricidade. Como na maioria desses bairros, aquelas pessoas, 
anteriormente, obtinham eletricidade ilegalmente de postes de rua para levar linhas a suas casas, lojas ou karkhanas (oficinas) para alimentar aparelhos domésticos ou comerciais. As redes de empreiteiras privadas e funcionários de baixo escalão da Empresa Municipal, que eram rotineiramente subornados, tinham garantido que os moradores não enfrentassem acusações criminais por roubo de energia. Agora, com a privatização, eles estavam descobrindo que as regras do jogo tinham mudado completamente. Sanjeev Gupta usou seu cargo de presidente do comitê local do partido do Congresso para organizar uma reunião (em algum momento de 2005) - entre os representantes da localidade e o funcionário encarregado da divisão local da empresa (BSES) -, a fim de discutir a questão do roubo de eletricidade e assédio. Depois que a eletricidade foi privatizada, houve um grande movimento na cidade para instalar medidores e impedir o roubo de eletricidade. No entanto, colônias como Punjabi Basti, onde Gupta reside, foram deixadas fora dos planos. Gupta e alguns outros membros da Associação de Moradores se reuniram com dois funcionários da empresa de eletricidade para defender a regularização do serviço. Na reunião, Sanjeev Gupta disse ao funcionário:

Senhor, temos pedido o fornecimento regular de eletricidade, mas vocês não aprovam medidores para nós. Além disso, vocês apresentam denúncias, e os policiais nos tratam como criminosos. Eles vêm e agarram a pessoa pelo pescoço, como se ela tivesse cometido um crime grave, como se fosse um assassino. Que tipo de justiça é essa?

0 funcionário respondeu que seus registros mostravam quanta eletricidade tinha sido consumida naquela localidade e o dinheiro arrecadado com isso. Ele disse, com veemência: "Com base nisso, eu afirmo que eu tenho provas de que as pessoas estão roubando - elas são ladras”. Gupta respondeu: "Senhor Ji, como o senhor pode nos chamar de ladrões? Se vocês não nos dão energia elétrica por não sermos uma colônia autorizada, as pessoas vão obter eletricidade por qualquer meio. Então por que chamá-las de ladras?"

Os funcionários da empresa demonstraram entender a dificuldade, porém havia um grande problema: como identificar corretamente as casas para a instalação de medidores? Os endereços eram todos aleatórios, e não havia números nem nomes de ruas. 0 funcionário aconselhou Gupta e sua delegação a obterem um mapa autorizado da área, com nomes de ruas e endereços para cada casa; sem esse mapa, ninguém conseguiria saber quem é responsável pelo pagamento das contas de energia elétrica.

Em seguida, Sanjeev Gupta e alguns outros líderes organizaram reuniões na área e convenceram a maioria das famílias a contribuir com 200 rúpias por família para encomendar um mapa. Depois de muitas dificuldades, devido à topografia da área e porque as casas não estavam em um nível único, uma empresa privada de arquitetos finalmente fez um mapa. Após uma troca de muitas cartas, abaixo-assinados e pressão do gabinete do ministro-chefe, o urbanista da empresa municipal finalmente aprovou o mapa. Isso permitiu que a BSES elaborasse uma lista de consumidores e instalasse medidores nas casas, após aumentar o fornecimento de eletricidade através da instalação de sete transformadores na área. No processo, cada casa recebeu um número e um endereço.

$\mathrm{Eu}$ não quero sugerir que todas essas ações - a elaboração do mapa, a atribuição de novos números, a instalação dos trans- 
formadores -, tenham sido alcançadas por meio de acordos aos quais se chegou através do discurso deliberativo racional. Foram feitas acusações na localidade, de que nem todo o dinheiro coletado fora devidamente contabilizado. Houve brigas sobre a localização exata dos transformadores - e um menino foi eletrocutado em um acidente trágico. Todavia, a ameaça mais grave a Sanjeev Gupta não veio publicamente, mas de muitas formas ocultas, da rede de "empresários" que anteriormente forneciam eletricidade ilegalmente e cujo negócio foi prejudicado ${ }^{7}$. Um dia, quando estava descrevendo os esforços que eles tiveram que fazer para completar o projeto, Sanjeev Gupta se engasgou subitamente e seus olhos se encheram de lágrimas. Ele disse: "Eu até fui atacado uma noite, quando voltava para casa. Um homem me abordou com um revólver e me disse para parar essas atividades”. Quando questionado sobre quem eram seus agressores, ele não revelou os nomes, mas respondeu que eram as mesmas pessoas que estavam se beneficiando das ligações ilegais e cujo dhandha (trabalho ilegal) teria sido interrompido. Eu perguntei se ele havia relatado esse incidente à polícia e ele respondeu: "Não, a polícia local está sempre do lado deles”. Preocupados com sua segurança, perguntei como ele cuidaria dessa ameaça, e ele respondeu:

Eu disse que não sou um homem fechado com o [Partido do] Congresso. Eu estou no Partido porque não posso passar sem ele. Portanto, quem está em cima foi informado e deve ter falado com eles, afinal, os que estavam me intimidando também fazem parte do mesmo esquema.
Era característico do modo de Sanjeev Gupta contar uma história que ele se recusasse a dar nomes dos que o haviam intimidado ou ameaçado. Claramente, ele vivia e trabalhava em um contexto em que as pessoas levavam uma vida cheia do que ele considerava corrupção, roubo e extorsão. Por exemplo, ao descrever um processo de demolição de barracos que acontecia em um bairro adjacente, no qual muitas pessoas pobres perderam suas moradias, ele previu que elas voltariam e reocupariam a terra, mas que teriam que pagar novamente aos mesmos que as haviam encorajado a ocupar a terra desocupada na primeira vez. "São as mesmas pessoas que haviam permitido que elas ocupassem essa terra pela primeira vez, pagando-lhes uma taxa de extorsão e, em seguida, colocaram na rua os esquadrões de demolição, e agora vão tirar dinheiro delas novamente", disse ele. Ele acrescentou: "Você acha que todas as bhu mafia (as máfias de terras) vêm de fora, com os grandes lobbies da construção, mas também há uma máfia $b h u$ local, que opera desde dentro". Certa vez, durante uma discussão sobre uma casa próxima que estava sendo reformada com materiais caros, eu tentei sugerir o nome de um destacado líder local que provavelmente estaria se beneficiando com as atividades de construção ao extorquir algum tipo de "taxa de proteção". "Foi você que disse o nome dele, não eu", disse Sanjeev, e depois acrescentou: "Talvez eu tenha dito que ele é $60 \%$ bom e $40 \%$ mau". 0 sentimento geral era de que as relações de proximidade exigiam que se enxergassem algo bom e algo ruim em todos.

7. Por razões óbvias, não foi possivel localizar as pessoas que constituiam essa rede, mas alguns funcionários da antiga Delhi Vidyut Board estavam envolvidos. 


\section{Um salto final}

Histórias como as que eu enumerei nos dizem como a corrupção se torna parte da possibilidade da própria vida nesses bairros, mas nunca está completamente normalizada ou naturalizada. Como a história de Premchand sobre o inspetor do sal, que nos deixa com uma inquietação profunda pela maneira em que honestidade e corrupção não são opostos tão claros, mas estão em um emaranhado de relações, eu também descobri que, enquanto era fácil falar da corrupção que envolvia grandes somas em dinheiro e grandes figuras do mundo político e empresarial, era muito mais difícil falar para os meus interlocutores, exceto em sussurros, da corrupção que fazia parte de seu próprio ambiente ${ }^{9}$. Não era simplesmente uma questão de contradições entre a ética impessoal da ação governamental e a ética pessoal das obrigações de parentesco, mas sim uma questão de reconhecer que o que sustentava a vida nesses bairros de baixa renda, onde a água não flui simplesmente abrindo-se a torneira, nem a eletricidade ligando um interruptor, faz com que se assuma uma posição diferente daquela gerada através de sensibilidades da classe média diante de perguntas sobre o que é legítimo e o que é ilegítimo.

Permitam-me dar um salto final e argumentar que, enquanto os atores que se manifestam nos dramas políticos sobre corrupção no cenário nacional têm uma ideia um tanto simplista do que constitui o Estado, as pessoas que eu conheço das favelas em Deli têm uma compreensão mais matizada, que reconhece abertamente as contradições em que estão enredados os seus próprios discursos sobre corrupção, honestidade e transparência. É assim que eu entendo como o viver em terras que elas reconhecem como ilegalmente "ocupadas" implica tirar eletricidade dos cabos de alta tensão, pressionar MPs e MAs para poder escavar poços e obter água, mesmo reconhecendo que isso viola a lei, e tudo isso as faz sentir que são acusadas aos olhos de alguns legisladores supostamente honestos. No entanto, elas têm uma resposta totalmente lúcida às acusações de corrupção feitas contra elas por burocratas: o que o pobre vai fazer? Ele só está tentando ganhar rozi-roti (renda para se alimentar). Ele está, de alguma forma, alimentando sua esposa e seus filhos - isso certamente não pode ser ilegítimo.

Assim, há otimismo com relação à possibilidade de contornar os burocratas e a lei, ao mesmo tempo em que há melancolia diante do fato de que a própria vida corrompe. Como o inspetor de Premchand, que, ao vestir a farda fica possuído pela voz da honestidade, eles também podem, por vezes, sentir-se entusiasmados com a aspiração de viver uma vida completamente honesta. Isso ficou claro para mim no entusiasmo sobre os slogans do AAP. Como comentou Ghulam Ali, o líder muçulmano que se descreveu como Shakuni Mama, sobre a vitória do AAP, quando lhe fiz uma

8. Anjaria (2011) faz uma observação semelhante em relação à corrupção cotidiana como algo que proporciona um espaço de negociação para vendedores ambulantes que reivindicam direitos a espaços na cidade, mas o trabalho do autor, embora sutil, não capta a ambiguidade com relação às ações dos próprios pobres. Não tenho espaço para me aprofundar na questão aqui, mas uma comparação com membros de classe média alta ou pessoas relativamente ricas mostraria que as violações de, digamos, regras de construção em Deli, evocam os direitos de indivíduos abastados sem reconhecer a corrupção envolvida. 
breve visita no inverno de 2014: "do din ki chandani, phir andheri raat" (luar por dois dias e, depois, noite escura). As pessoas nas áreas da cidade que eu conheço consideram suas próprias aspirações para a vida e por um futuro melhor para seus filhos como inevitavelmente emaranhadas no complexo da corrupção. Enquanto isso, como eles dizem, podemos ficar felizes porque, mesmo que o próprio tempo venha a corromper os movimentos que parecem tão imaculados hoje em dia, pelo menos podemos apreciá -los enquanto durarem.

Em seu perspicaz comentário sobre os artigos reunidos em Contributions to Indian Sociology (2015), onde este artigo foi publicado originalmente, Charles Halliseynos pede que consideremos a possibilidade de as noções de venalidade e venialidade estarem unidas de alguma forma, não só em termos de semelhança fonética, mas também de uma relação de "proximidade" entre si no contexto da vida quotidiana. 0 que Hallisey está propondo é que, assim como Sanjeev Gupta, nós também nos afastemos do desejo de "julgar" para desenhar fronteiras claras entre as pequenas tentações, que nos desviam do caminho, e os grandes pecados venais que convidam à contemplação de algum inferno que nos espera. Na bela história budista que ele conta sobre o açougueiro e o touro, o Buda não questiona a correção do que o açougueiro disse sobre a necessidade de cuidar de sua família, nem se afasta simplesmente do sofrimento do touro. Em vez disso, ao procurar uma maneira em que o touro pudesse ser poupado e o açougueiro pudesse cuidar de sua família, o Buda evoca uma sensibilidade moral que não se baseia em julgamentos estrondosos do bem e do mal, mas em superar uma dificuldade da realidade em que as possibilidades de certo e errado coexistem. 0 fato de eu ter encontrado a minha âncora teórica no romance de Premchand também é evidência de que o nosso trabalho com conceitos como corrupção, seja em nível de indivíduo ou como um aspecto de um determinado meio social, não precisa exigir que saltemos a um reino rarefeito do pensamento. Como observou Wittgenstein:

Estamos sob a ilusão de que o que é peculiar, profundo, essencial em nossa investigação reside em sua tentativa de captar a essência incomparável da linguagem. Ou seja, a ordem existente entre os conceitos de proposição, palavra, prova, verdade, experiência e assim por diante. Essa ordem é uma superordem entre, por assim dizer - superconceitos. Considerando que, obviamente, se as palavras 'linguagem', 'experiência' e 'mundo' têm utilidade, ela deve ser tão humilde quanto a das palavras 'mesa', 'lâmpada' e 'porta' (1973 [1958], p. 97).

Usando palavras humildes que descrevem a vida em circunstâncias humildes, espero ter mostrado que podemos chegar a uma compreensão ao perder nosso apego à profundidade moral e intelectual, como Premchand também estava inclinado a mostrar em seus contos e novelas.

\section{Referências}

ANJARIA, J. Ordinary States: everyday corruption and the politics of space in Mumbai. American Ethnologist, v. 38, n. 1, p. 58-72, 2011.

AUGE, M. La vie en double: Ethnologies, voyages, ecriture. Paris: Payotet Rivages, 2011.

BETLEM, H. Negotiating ritual duty in degenerate times: the goddess matthama and the legal Secular in rural south India. American Ethnologist, v.42, n.1, p. 131-143, 2015. 
CRAPANZANO, V. Imaginative Horizons: an essay in literary-philosophical anthropology. Chicago: The University of Chicago Press, 2003.

DAS, V. Life and Words: Violence and the Descent into the Ordinary. Berkeley: California University Press, 2007.

Action and Expression: recounting household events. In: DAS, V.; JACKSON M.; KLEINMAN; SINGH B. (Orgs.) The Ground Between: anthropologists engage philosophy. Durham: Duke University Press, 2014, p. 279-305.

DAS, V.; WALTON, M. Forthcoming: political leadership and the urban poor. Current Anthropology, Chicago, v. 56, n. S11, out. 2015 Disponível em: <https://assets.publishing.service.gov.uk/media/ 57a08a1ee5274a27b200042b/60724_DAS_WALTON_PAPER.pdf>.

DESARDAN, J.P.O. A moral economy of corruption in Africa? The Journal of Modern African Studies, v. 37, p. 25-52, 1999.

FASIN, D. True Life, Real Lives: Revisiting the Boundaries between Ethnography and Fiction. American Ethnologist, v. 44, n. 1, p. 40-55, 2014. GUPTA, A. Blurred Boundaries: the discourse of corruption, the culture of politics, and the imagined state. American Ethnologist, v. 22, n. 2, p. 375-402, 1995.

GUPTA, S. How politics works for the poor: a grassroots politician and congress party worker contests two of AAP's big assertions. Indian Express, 27 jan. 2014.

JACKSON, M. The Other Shore: essays on writers and writing. Berkeley: California University Press, 2013.

PARRY, J. The crisis of corruption and the idea of India: a worm's eye view. In: PARDO, I. (Org.). Morals of Legitimacy: Between Agency and System. New York: Berghann, 2000, p. 27-56.

PREMCHAND, M. Namak ka Daroga. Delhi: Rajpal and Sons, 2009.

SELBY, D. Experiments with Fate: buddhist morality and human rights in Thailand. In: CHATTERJI, R. (Org.). Wording the World: Veena Das and scenes of inheritance, New York: Fordham University Press, 2015, p. 128-153.

SHAH, A. In the Shadows of the State: indigenous politics, environmentalism, and the Iinsurgency in Jharkhand, India. Durham: Duke University Press, 2010 .

SNEATH, D. Transacting and Enacting Corruption, obligation and the use of monies in Mongolia. Ethnos-Journal of Anthropology, v.71, n. 1, p. 89-112, 2006.

VANITA, R. (Org). The Co-wife and Other Stories. Delhi: Penguin Books, 2008.

WAGNER, R. The Fractal Person. In: GODELIER, M.; STRATHERN, M. (Orgs.) Big Men and Great Men: personifications of power in Melanesian. Cambridge: Cambridge University Press, 1991, p. 159-73.

WITTGENSTEIN, L. Philosophical Investigations. Tradução de G. E. M. Anscombe, 2. ed., Oxford: Blackwell, 1973. 
RESUMO

Este artigo analisa como podemos entender a corrupção como algo ancorado em práticas comuns e cotidianas. Evitando a dupla armadilha da condenação e do relativismo, ele mostra como os pobres urbanos consideram que a aspiração a uma comunidade política purificada cria as condições de possibilidade nas quais o espaço político de ação se fecha para aqueles que estão dentro do que se poderia chamar de complexo da corrupção. Movendo-se entre a etnografia e a literatura, o texto presta muita atenção a formas de fala, bem como a formas de ação, e demonstra que os pobres têm uma compreensão muito mais matizada do Estado do que a maneira como ele é representado no trabalho de intelectuais e ativistas públicos.

\section{PALAVRAS-CHAVE}

Corrupção. Pobres. Estado. Literário. Etnografia.

\section{ABSTRACT}

This article analyses how we might understand corruption as anchored in ordinary, everyday practices. Avoiding the double trap of condemnation and relativism, it shows how the urban poor see the aspiration for a purified polity as creating the conditions of possibility in which the political space of action closes down for those within what one might call a corruption complex. Moving between ethnography and literature, the article pays close attention to forms of talk as well as forms of action and demonstrates that the poor display much more nuanced understanding of the state as compared to the way it is represented in the work of public intellectuals and activists.

\section{KEYWORDS}

Corruption. Poor. State. Literary. Ethnography. 